\title{
Prognosis and management of Crohn's disease in the over-55 age group
}

\author{
RS Walmsley, CD Gillen, RN Allan
}

\section{Summary}

The course, prognosis and management of 62 patients with Crohn's disease aged 55 years or over at diagnosis has been reviewed. The distal ileus was the commonest site of disease in the older patient, where the characteristic presentation was acute after initially mild symptoms. Early local resection was often required, particularly where there was diagnostic doubt or suspicion of caecal malignancy. Recurrence rates were much lower in the older patient than after resection in younger patients. Medical treatment played a minor role in the management of patients with distal ileal disease, in part because stricture formation was present at diagnosis and the acute nature of symptoms at presentation led to early surgical treatment. Colonic Crohn's disease was usually confined to the distal or left side of the colon and initially could be difficult to distinguish from diverticular disease. Extensive colonic Crohn's disease was rare. The apparently limited disease was not necessarily associated with a good prognosis, since disease at this site sometimes progressed rapidly, necessitating urgent surgical resection.

Medical treatment (corticosteriod therapy, with or without azathioprine) was usually effective initially for treatment of symptomatic colonic Crohn's disease, but sustained remission was rare. Those patients with persistent symptoms were restored to good health with surgical treatment but at a price, in that nearly half eventually required a permanent stoma.

Keywords: Crohn's disease

Crohn's disease typically presents in young adult life, but also occurs in the older patient. Indeed, some reports suggest a bimodal distribution with a second peak occurring between the ages of 50 and $70 .{ }^{1}$ The increasing incidence of both Crohn's disease and the proportion of elderly people in the population, enhances the significance and importance of Crohn's disease in this age group. Early studies of prognosis suggested that Crohn's disease might be more aggressive in the older patient, ${ }^{2}$ but since the recognition of Crohn's colitis in $1960,{ }^{3}$ and its distinction from ischaemic colitis in $1963,{ }^{4}$ more recent evaluation of Crohn's disease in the older patient has suggested a relatively benign course, ${ }^{5,6}$ although the total number of patients reviewed in these studies was small.

We have undertaken an analysis of the clinical presentation, course, and prognosis in a series of 62 consecutive patients aged 55 years or over at diagnosis of their Crohn's disease between 1970 and October 1993.

\section{Methods}

The case records were reviewed of 62 patients (30 male) who were at least 55 years of age at presentation, identified from among a series of more than 850 Crohn's disease patients under long-term review. Only patients diagnosed from 1970 onwards were included in this study, when the distinction between ischaemic and Crohn's colitis was fully appreciated, and also because during this period the patients had received consistent joint medical and surgical care.

\section{Results}

The mean age at onset, diagnosis, duration of follow-up and mortality are summarised in table 1 . The male to female ratio was $1: 1.2$. The distribution of disease at presentation is summarised in table 2. Patients with terminal

Table 1 Mature onset Crohn's disease: patient characteristics $(n=62)$

\begin{tabular}{llll}
\hline & Median & Mean & Range \\
\hline $\begin{array}{l}\text { Age at diagnosis (years) } \\
\text { Age of onset of }\end{array}$ & 67.1 & 68.35 & $56.9-92$ \\
$\quad$ symptoms (years) & & 67 & $56-82$ \\
$\begin{array}{l}\text { Interval onset to } \\
\text { diagnosis (months) }\end{array}$ & 6 & 16.3 & $0-186$ \\
$\begin{array}{l}\text { Follow-up (years) } \\
\text { Age at death (years) }\end{array}$ & 10 & 8 & $0.1-20$ \\
\hline
\end{tabular}

Table 2 Mature onset Crohn's disease: distribution of disease $(n=62)$

\begin{tabular}{lc}
\hline & $\begin{array}{l}\text { Number of } \\
\text { patients (\%) }\end{array}$ \\
\hline Colonic disease (all sites) & $38(61)$ \\
Total or extensive colonic disease & $4(6)$ \\
Distal colonic disease & $22(35)$ \\
Other colonic disease & $3(5)$ \\
Left-sided colonic disease & $8(13)$ \\
Terminal ileum \pm right colon & $24(39)$ \\
Peri-anal disease alone & $1(1)$ \\
\hline
\end{tabular}


$+/-$ right colonic involvement at presentation constituted $39 \%$ of the total. In an earlier study of young patients aged 16 or less presenting to our unit from 1935 to $1980,56 \%$ had terminal ileal involvement. ${ }^{7}$ Total or extensive colonic involvement, defined as disease affecting at least four of either the right, transverse, descending, sigmoid colon or rectum, occurred in only four of our patients. Distal disease is confined to the rectum $+/-$ the sigmoid colon. Left-sided colonic disease includes the descending colon, sigmoid and rectum. Nineteen patients with colonic disease also had peri-anal disease $(50 \%)$. Only one patient with distal ileal disease also had perianal disease.

The prevalence of coexistent disorders is summarised in box 1 . Diverticular disease was common (45\%), particularly in patients with colonic Crohn's disease, as noted previously, ${ }^{8}$ although the prevalence is similar to that in the general population of this age. ${ }^{9}$ The other common problem was thrombo-embolic disease in $10 \%$ of patients, even after those with disorders predisposing to thrombophlebitis such as carcinoma, had been excluded. This is consistent with the recently observed increase in incidence compared with the general population. ${ }^{10}$

In common with recent reports of the association of smoking with Crohn's disease, ${ }^{11}$ $28(45 \%)$ of the total group were current smokers at diagnosis with a positive smoking history at some time in nearly two thirds $(63 \%)$, higher than the general population prevalence of around $50 \%$.

There were 25 deaths in total during followup, 14 male, seven disease-related. Table 3 summarises the standardised mortality ratios using sex- and age-specific mortality rates for England and Wales in 1990, assuming a Poisson distribution. There was no significant difference for either sex.

\begin{tabular}{|l|}
\hline $\begin{array}{l}\text { Mature onset Crohn's disease: } \\
\text { coexisting conditions ( } \boldsymbol{n}=62)\end{array}$ \\
\hline - diverticular disease 28 \\
- deep vein thrombosis/pulmonary embolus 6 \\
- peptic ulceration 6 \\
- sall stones 5 \\
- sacroileitis 2 \\
- osteoporosis 2 \\
- pyoderma gangrenosum 1 \\
- erythema nodosum 1 \\
\hline
\end{tabular}

Box 1

Table 3 Mature onset Crohn's disease: mortality

\begin{tabular}{lllll}
\hline & & & $\begin{array}{l}\text { Standard } \\
\text { mortality } \\
\text { ratio }\end{array}$ & $\begin{array}{l}95 \% \\
\text { confidence } \\
\text { intervals }\end{array}$ \\
\hline Male & 14 & 10.2 & 1.37 & $0.75-2.3$ \\
Female & 11 & 7.4 & 1.48 & $0.74-2.66$ \\
\hline
\end{tabular}

DISTAL ILEAL DISEASE +/ - ASCENDING COLON

The diagnosis was based on radiological and histological criteria in 12 (50\%), on radiological grounds alone in five cases, and histology alone in a further six. One patient had changes on barium enema examination consistent with the diagnosis of Crohn's disease which was confirmed at laparotomy with characteristic histological changes in the lymph nodes.

\section{Presentation}

Most patients presented with multiple symptoms including recurrent abdominal pain and weight loss, ${ }^{10}$ of whom four also had diarrhoea and two a palpable mass. Three patients presented with weight loss, diarrhoea and a mass but no pain. Presentation with isolated symptoms was uncommon and included diarrhoea (4), pain (2), weight loss (1), and symptomatic anaemia (1). Acute presentations included perforation (2) and acute obstruction (1).

\section{Medical management}

Because many patients came to resection soon after presentation, medical treatment was only used on a few patients pre-operatively. One patient with a narrow segment of terminal ileum was given prednisolone for six weeks with no improvement in symptoms and subsequently underwent resection. Four patients with long narrow strictures associated with recurrent colicky abdominal pain received no pre-operative medical therapy. Four patients required emergency laparotomy and in eight cases there was diagnostic doubt. One patient with a long terminal ileal stricture at presentation received medical therapy for nine years before undergoing resection. One patient with multiple entero-enteric fistulae around the terminal ileum received anti-diarrhoeals for 14.5 years before laparotomy revealed a disseminated carcinoid tumour. Five patients received medical treatment only and did not require surgical intervention. Two required a course of systemic steroids for symptomatic recurrent disease following resection.

\section{Surgical management}

Twenty patients had a laparotomy, four as an emergency and all but one underwent resection. The commonest indication for surgery was recurrent subacute obstructive symptoms $(47 \%)$, but the need to exclude malignancy was also an important indication for laparotomy $(37 \%)$. Seventeen came to resection within three months of presentation. In the other three patients the interval was one, nine, and 14.5 years, respectively.

Recurrent disease was uncommon (six patients), but when it did occur it was usually shortly after resection (in four, less than one year), the others suffering symptomatic recurrence at 2.5 and 12 years. However only one patient requiring a second resection three months after his first.

\section{Mortality}

During the period of follow-up there were eight deaths; ischaemic heart disease (2), stroke (1), 
disseminated carcinoma of the prostate (1), carcinoma of the oesophagus (1). One death was due to disseminated malignancy from a primary carcinoma of the caecum found at initial laparotomy in an elderly woman who had had symptoms attributable to her Crohn's disease for more than 15 years. The exact cause of death was not fully established in two cases.

One 68-year-old woman developed severe post-operative hyponatraemia with marked deterioration in her mental faculties such that she required rehousing in sheltered accommodation. Another woman with entero-enteric fistulae for 14.5 years underwent ileocaecal resection for relief of obstructive symptoms and was found to have a disseminated carcinoid tumour at this site.

\section{Current status}

Fifteen of the surviving patients are well, eight requiring anti-diarrhoeal medication. Two are receiving vitamin $\mathrm{B} 12$. One man has developed myelofibrosis and polycythaemia. The woman with a carcinoid tumour is terminally ill with a large pelvic mass.

\section{COLONIC DISEASE}

Only five of the 38 patients with colonic involvement were secondary referrals to the unit.

\section{Presentation}

Diarrhoea was the commonest presenting complaint occurring in 26 patients, accompanied by blood in the stool (13), or weight loss (11), peri-anal symptoms (4) and vaginal discharge (1). Five had altered bowel habit but no diarrhoea, of whom four had blood in their stools and two weight loss. Other presentations included, abdominal pain alone (2), pain with weight loss (1), peri-anal discomfort and incontinence (1), and one woman who presented with a right ileac fossa mass and colicky pain due to terminal ileal disease as well as bloody stools due to proctosigmoiditis.

\section{Diagnosis}

The diagnosis was established on histological and radiological grounds except for five based on histological evidence alone, while two had characteristic barium studies.

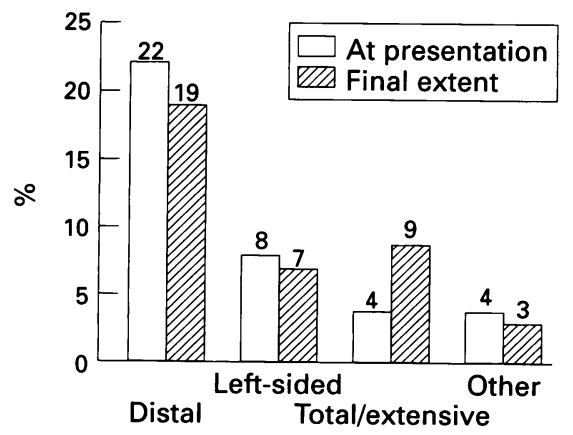

Figure 1 Distribution of colonic Crohn's disease
The initial and final distribution of disease is summarised in figure 1 . In most patients there was no change in the site or extent of the disease once the diagnosis had been established, despite a mean follow-up of 10 years. Four patients with initial disease apparently confined to the distal or left colon, and one with patchy disease developed extensive colonic Crohn's disease.

\section{Medical treatment}

More than half of this group received corticosteroids (55\%), with the addition of azathioprine in five. While initially there was usually a good response to therapy, only six patients had a complete or sustained remission. Surgical resection was needed in the majority to restore good health. Rectal corticosteroids alone were effective in three, and 5-acetylsalicylic acid preparations successfully treated five others.

\section{Surgical treatment}

More than half had definitive colonic resection (excluding drainage procedures for sepsis or local peri-anal surgery). The median time from diagnosis to the first resection was 1.3 years (mean 1.6, range 0 to 6.6). The indications are summarised in box 2 . The initial surgery and final outcome is summarised in figure 2 . Eight patients required a second resection and two required a third. Local resection with sigmoid colectomy was often undertaken in patients with left-sided disease, but half of them eventually came to panproctocolectomy because of symptomatic recurrence. Ileostomy alone was sometimes used in the severely ill and those loath to accept panproctocolectomy, but the benefit was usually short-lived.

The median interval between the first and second resections was 0.6 years (mean 0.6 , range 0.08 to 1.3 ).

\section{Mortality}

There were 17 deaths in this group during the period of follow-up. The unrelated deaths were due to ischaemic heart disease (3), pneumonia (3), pulmonary emboli (2, associated with carcinoma of the prostate and carcinoma of the bronchus), disseminated carcinoma of the thyroid (1) and septicaemia following emergency panproctocolectomy for perforation of ischaemic bowel (1). The seven disease-related deaths are summarised in table 4 . Two of the four post-operative deaths occurred among patients who were moribund at presentation. Two patients developed adenocarcinoma of

\begin{tabular}{|l|}
\hline $\begin{array}{l}\text { Indications for surgery in patients } \\
\text { with colonic disease }(\boldsymbol{n}=\mathbf{2 1})\end{array}$ \\
\hline - failed medical therapy 14 \\
- perforation 2 \\
- obstruction 2 \\
- entero-vesical fistula 1 \\
- ? malignancy 1 \\
\hline
\end{tabular}




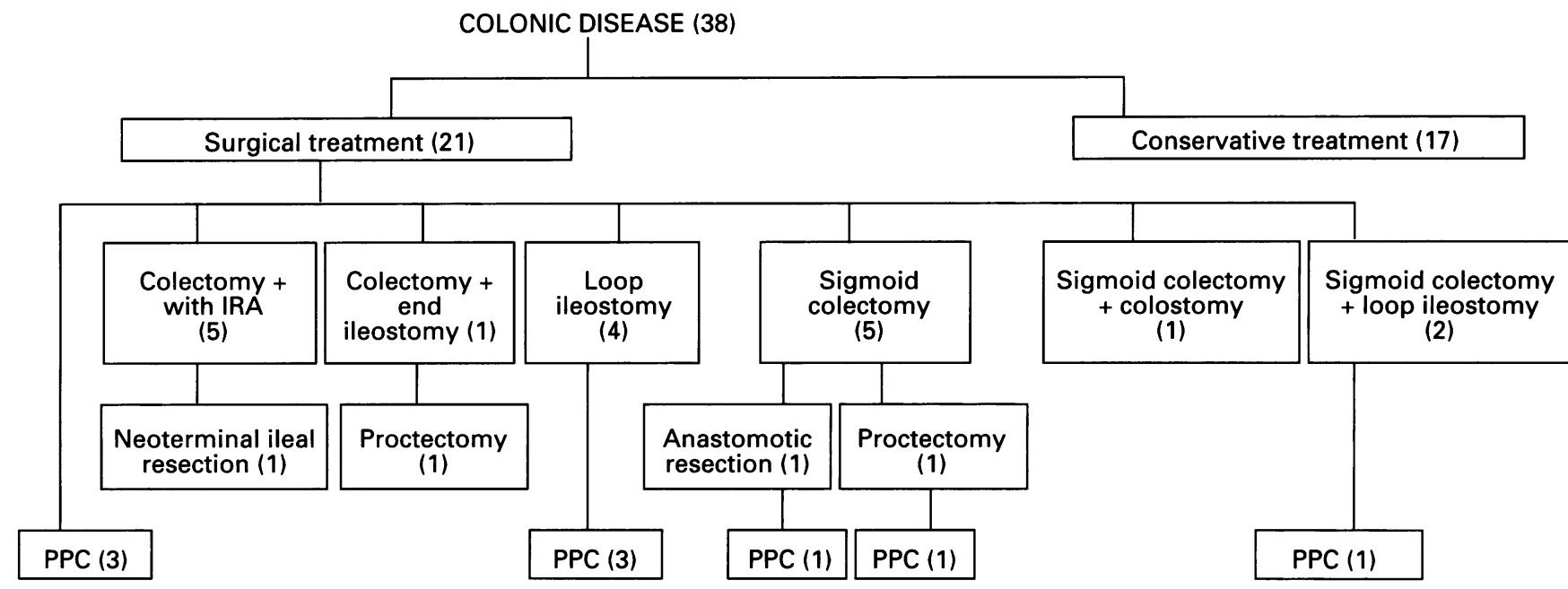

Figure 2 Treatment of colonic Crohn's disease. IRA=ileorectal anastomosis; PPC=panproctocolectomy; figures in parentheses are numbers of patients in each group

the large intestine, both unexpected findings. A Duke's A tumour was found at elective panproctocolectomy in a 67-year-old man with left-sided disease of five years duration. A 70year-old man with extensive colonic disease for eight years had a polyp removed endoscopically which histologically was a carcinoma insitu.

\section{Current status}

Of the 21 patients alive when last reviewed, 13 are on no medication at all, three take oral 5acetylsalicylic acid preparations, including one who also takes rectal steroid preparations, three receive anti-diarrhoeal agents, two oral prednisolone and one 61-year-old woman who initially had proctosigmoiditis is on a reducing course of steroids prescribed for an exacerbation of her disease which now involves the transverse colon. A 73-year-old woman who takes $2.5 \mathrm{mg}$ of prednisolone daily to control her diarrhoea also has myelodysplasia, requiring frequent blood transfusions.

\section{Discussion}

It is often difficult to establish the diagnosis of Crohn's disease in the older patient because the disease is uncommon and the initial symptoms are often mild or atypical. The mean interval between onset of symptoms and establishing the diagnosis in this series was just over 16 months (range up to 15 years). The explanation for the delay in diagnosis was usually that the symptoms were initially mild and non-specific and only became severe enough immediately before presentation to warrant medical attention.

We found an equal male to female ratio in patients with Crohn's disease in the older population and could not confirm earlier reports of a female predominance, ${ }^{1,12-14}$ perhaps because only small numbers of patients were studied previously.

\section{DISTAL ILEAL DISEASE}

After initially mild, often atypical, symptoms, patients with distal ileal disease then present with focal, clear-cut symptoms; usually subacute intestinal obstruction from underlying stricture formation. A small but significant number of patients present acutely. Five of the 24 patients $(21.7 \%)$ with distal ileal disease presented with a right iliac fossa mass; this percentage was higher than that in an earlier review of patients of all ages with distal ileal Crohn's disease presenting to this unit between 1970 and 88 (which includes some patients in this present series), where only 12 of 139 patients $(8.6 \%)$ had such a finding. ${ }^{15}$ Laparotomy may be needed when the diagnosis is uncertain, particularly if the radiological findings are difficult to interpret or the clinical presentation is unusual.

Table 4 Crohn's disease related deaths (colonic)

\begin{tabular}{|c|c|c|c|}
\hline $\begin{array}{l}\text { Age at } \\
\text { death (years) }\end{array}$ & Sex & Cause of death & $\begin{array}{l}\text { On systemic steroids } \\
\text { at time of death }\end{array}$ \\
\hline 82 & $\mathbf{F}$ & Septicaemia following elective panproctocolectomy & No \\
\hline 72 & $\mathbf{M}$ & Septicaemia following emergency colectomy for obstruction & Yes \\
\hline 63 & $\mathbf{M}$ & $\begin{array}{l}\text { Septicaemia from septic arthritis complicated by short bowel } \\
\text { syndrome }\end{array}$ & Yes \\
\hline 73 & $\mathbf{M}$ & Septicaemia following colectomy for perforation & Yes \\
\hline 67 & $M$ & $\begin{array}{l}\text { Bronchopneumonia and renal failure following elective } \\
\text { panproctocolectomy }\end{array}$ & No \\
\hline 81 & $\mathbf{M}$ & $\begin{array}{l}\text { Septicaemia following perineal gangrene arising from a perineal } \\
\text { abscess }\end{array}$ & No \\
\hline 85 & $\mathbf{F}$ & $\begin{array}{l}\text { Small bowel volvulus } 11 \text { years after an elective panproctoco- } \\
\text { lectomy, plus an incidenal carcinoma bronchus }\end{array}$ & No \\
\hline
\end{tabular}




\begin{tabular}{|l|}
\hline Summary points \\
\hline Distal ileal disease \\
- is the most common site \\
- delay in diagnosis means characteristically \\
acute presentation \\
- recurrent disease is uncommon and rarely \\
requires further resection \\
Colonic disease \\
- usually distal \\
- medical management is often difficult \\
operative intervention in $55 \%$ of cases, of \\
whom over half require panproctocolectomy \\
\hline
\end{tabular}

Box 3

The initial resection rate $(79 \%)$ is similar to that reported in earlier reviews of 45 patients from this unit $(77 \%)^{5}$ and consistent with operative rates for all ages, both here $(79 \%$ of 139 cases) ${ }^{15}$ and in the Cleveland Clinic series (91.5\% of 246 patients). ${ }^{16}$ Recurrent distal ileal Crohn's disease requiring resection is rare in the older patient. Only one of the 19 patients treated by resection, with a mean follow-up of eight years, required a second resection compared to 33 out of 110 patients in an earlier study of patients of all ages treated in Birmingham with a similar mean follow-up of 10 years. $^{15}$

\section{COLONIC DISEASE}

This study confirms that colonic Crohn's disease in the older patient is usually confined either to the rectum or the sigmoid colon, while total or extensive colitis is uncommon. However, it cannot be assumed that the apparently limited disease is associated with a good prognosis or benign outcome. Severe exacerbations of apparently distal disease need intensive medical treatment and even so response is often poor, perhaps because of an

1 Rose JDR, Roberts GM, Williams G, Mayberry JP, Rhodes J. Cardiff Crohn's disease jubilee: the incidence over 50 years. Gut 1988; 29: 346-50.

2 de Dombal FT, Burton IL, Clamp SE, et al. Short term course and prognosis of Crohn's disease. Gut 1974; 15 435-43.

3 Lockhart-Mummery HE, Morson BC. Crohn's disease (regional enteritis) of the large intestine and its distinction from ulcerative colitis. Gut 1960; 1: 87-105.

4 Boley SJ, Schwartz S, Lash J, et al. Reversible vascular occlusion of the colon. Surg Gynecol Obstet 1963; 116: 5360.

5 Fabricius PJ, Gyde SN, Shoulder P, et al. Crohn's disease in the elderly. Gut 1985; 26: 461-5.

6 Harper PC, McAuliffe TL, Beeken WL. Crohn's disease in Harper PC, McAuliffe TL, Beeken WL. Crohn's disease in
the elderly. A statistical comparison with younger patients the elderly. A statistical comparison with younger patients matched for sex an

7 Puntis J, McNeish AS, Allan RN. Long term prognosis of Crohn's disease with onset in childhood and adolescence. Gut 1984; 25: 329-36.

8 Ritchie JK, Lennard-Jones JE. Crohn's disease in the distal large bowel. Gastroenterology 1976; 11: 433-6.

9 Hughes LE. Post-mortem survey of diverticular disease of the colon. Gut 1969; 10: 336-51.

10 Webberley MJ, Hart MT, Melikian V. Thromboembolism in inflammatory bowel disease; role of platelets. Gut 1993; 34: $247-51$. additional ischaemic element in the affected colon.

We found that local resection of colonic disease in the older patient often only brought temporary improvement and early recurrent disease in the residual colon was common, so that an initial local resection was often followed by panproctocolectomy. Perhaps in some patients this might have been undertaken initially. Emergency surgical treatment in the older patient was associated with a poor outcome so that, wherever possible, elective surgery is preferable and likely to minimise morbidity. It follows that better surgical results could be achieved at the price of some patients accepting a permanent stoma.

This study suggests that colonic Crohn's disease is not the benign disease that recent reports have suggested. ${ }^{5,6,12}$ While the patients have predominantly distal colonic disease, the overall operative rate in this study of $55 \%$ is similar to that seen in 360 patients of all ages presenting to our unit between 1944 and 1986 . Andrews et $a l^{17}$ showed an operative intervention rate of $62 \%$ at 10 years and a populationbased study from Denmark found a rate of $55 \%$ after a mean follow-up of 10 years. ${ }^{18}$ Over half of those who underwent resection eventually required a panproctocolectomy; this is similar to $41 \%$ of 270 surgically treated patients of all ages with colonic Crohn's disease $^{12}$ and seven of 15 patients described by Tchirkow from the Cleveland Clinic. ${ }^{14}$ The fact that only three of the 10 panproctocolectomies were performed as the initial operation suggests that a more radical approach might be appropriate when faced with persistent severe symptoms, even when the disease is confined to the distal colon. While the high morbidity may in part reflect the inherent biases of a hospital-based series, there were only five secondary referral patients included in the current study.

11 Tobin MV, Logan FA, Langman MJS, McDonnell RB, Gilmore IT. Cigarette smoking and inflammatory bowe disease. Gastroenterology 1987; 93: 316-21

12 Softley A, Myren J, Clamp SE, Bouchier IAD, Watkinson $G$, de Dombal FT. Inflammatory bowel disease in the lderly patient. Scand $\mathcal{f}$ Gastroenterol 1988; 23 (suppl 144): 31: $27-30$.

13 Lee FI, Giaffer M. Crohn's disease of late onset in Blackpool. Postgrad Med f 1987; 63: 471.

14 Tchirkow G, Lavery IC, Fazio VW. Crohn's disease in the elderly. Dis Colon Rectum 1983; 26: 177-81.

15 Andrews HA, Keighley MRB, Alexander-Williams J, Allan RN. Strategy for management of distal ileal Crohn's disease. RN. Strategy for management

16 Farmer RG, Whelan G, Fazio VW. Long-term follow up of patients with Crohn's disease. Relationship between the clinical pattern and prognosis. Gastroenterology 1985; 88: $1818-25$.

17 Andrews HA, Lewis P, Allan RN. Prognosis after surgery for colonic Crohn's disease. Br $\mathcal{F}$ Surg 1989; 76: 1184-90.

18 Binder V, Hendriksen C, Kreiner S. Prognosis in Crohn's disease based on the results from a regional patient group from the County of Copenhagen. Gut 1985; 26: 146-50. 